IP Periodica Polytechnica

Transportation Engineering

44(1), pp. 1-4, 2016

DOI: $10.3311 /$ PPtr. 8086

Creative Commons Attribution (i)

RESEARCH ARTICLE

\section{Sign-in-time Based Info-communication System for Collecting Selective Waste}

\author{
Ádám Titrik ${ }^{1 *}$
}

Received 19 March 2015; accepted after revision 18 May 2015

\begin{abstract}
In the field of municipal waste, expanding cities and growing trend of the population have increasing and problematic effects. Improperly emptied containers jeopardize the possibility of the development of cleaner and more liveable city. Directly occurring problems can be the environmental and road-safety aspects during reaching the containers. Through the application of modern technologies, there are opportunities to apply sign-in-time frequency-based communication. This leads not only to the optimization of the collection route but also to the reduction of the above mentioned problems and problematic effects.
\end{abstract}

\section{Keywords}

route optimization, sign-in-time system, measuring technology, info-communication, waste collection

\footnotetext{
${ }^{1}$ Department of Automotive and Railway Engineering,

Széchenyi István University,

H-9026 Györ, Egyetem Tér 1., Hungary

Researcher ID: F-3073-2015

*Corresponding author, e-mail: titrika@sze.hu
}

\section{Introduction}

This study's main objectives are route optimization, fuel saving and emission reduction. The other objective is to introduce a theoretical system that can define a higher level waste gathering system based on the previous objectives, so it can detect the saturated containers and ignore the unjustified emptying. The solution is to place saturation measuring equipment and connect it to the route planning center with sign-in-time based communication system. This allows the optimization of gathering routes and the optimization of the number of emptyings. By the use of the sign-in-time based info-communication system it is possible to add extra destinations during the gathering method, so the route plan can be redefined.

According to environmental standards, environmental pressure and recycling, selective waste gathering stations were created in the cities and waste specific containers were placed on these stations (Barlishe and Baetz, 1996; Caruso et al., 1993). The emptying order currently based on experiences only and the gathering routes aren't optimized for every carriage. There is more and more pressure on waste gathering companies within the European Union, to raise their services quality for lower costs.

Service optimization, both in terms of quality and costs can only be achieved using advanced decision support tools, modelling the many different components of an integrated waste management system (Tadic, 2015; Ko et al., 2014; MacDonald, 1996).

Studies were made in different regions of the world - Turkey, India, USA -, according to them fuel saving (Tóth-Nagy et al., 2006), reduced gathering-routes (Chowdhury et al., 2014) and time are possible to reach with the use of different waste gathering support software - for example: GIS 3D modelling, ArcGis ${ }^{\circledR}$, and RouteViewPro ${ }^{\text {TM }}$ (Fioruccia, 2003; Ghose et al., 2006). Further developments were made to reduce emission and to minimize energy consumption. - For example artificial intelligence in vehicle engine and the use of developed diagnostic systems (Titrik et al., 2011).

\subsection{Review of applied solutions nowadays}

By the development of computer software and GPS technology it became possible to optimize different factors in traffic: 
fuel saving, routes, travel time (Mihály et al., 2014; Péter and Fazekas, 2014; Tettamanti et al., 2015).

Using GIS 3D modelling in the island of Santo Antao, Republic of Cape Verde, an area with intense relief, they achieved up to $52 \%$ fuel savings compared to the shortest distance, even travelling a 34\% longer distance. Apaydin and Gonullu utilised RouteViewPro ${ }^{\mathrm{TM}}$ to achieve a $24.6 \%$ reduction in distance and $44.3 \%$ in total time travelled in the city of Trabzon, Turkey. Ghose et al. (2006), on the other hand, used ArcGIS $®$ Network Analyst to successfully minimise the distance and cost of waste transportation to landfill in the city of Ansasol, India. Using WasteRoute a $10 \%$ reduction in the number of collection trips was achieved in the area of Elgin, Illinois, USA. (Jovičić, 2010; Tavares et al., 2008; Simonetto and Borenstein, 2006).

In addition, there are studies to expand the gathering vehicle's store capacity to reduce the number of the turn-around.

GYÖR-SZOL Ltd. in Hungary - owned by Györ city - gave an opportunity to report the containers' saturation on a free to call the telephone number, painted on the side of the containers.

These systems assisted to the optimal route definition but didn't answer that which container emptying is reasonable. The study's objective is to present a sign-in-time based info-communication system's principles, that can communicate with the route planning center about the saturation data of the containers and this system can modify the route live during the gathering method.

\section{Review of the sign-in-time based info- communication system}

The system presented in this paper is based on the sign-intime info-communication and the GIS technology.

This new gathering method has been patented. By an ongoing pilot project, the patented process can be implemented and proved (Titrik, 2011).

There is an opportunity for realistic, life-like testing by GYÖRSZOL Ltd., owned by Györ City. The system consists of the following three major parts:

1. containers' saturation measurement,

2. containers' information database,

3. definition of optimal routes and emptying.

The sign-in-time based communication between the gathering vehicle and the route planning center is very important because of the different compression rate of waste types has a big influence on container emptying and vehicle saturation. By the mentioned info-communication system the issued route plan can be, modified during the gathering method as they can add extra destinations to the plan. After the optimization and redefinition of the route, the gathering vehicle receives a modified route.

The selective waste gathering vehicle's loading volume is about $22 \mathrm{~m}^{3}$. During the gathering procedure, the volume of the waste doesn't reach the maximum level without compression. So we can use the following compression scale numbers to get the real transporting volume of the different type of waste (Table 1).

Table 1 Real transporting volume

\begin{tabular}{llll}
\hline $\begin{array}{l}\text { Type of } \\
\text { waste }\end{array}$ & $\begin{array}{l}\text { Comp. } \\
\text { scale }\end{array}$ & $\begin{array}{l}\text { Real volume in a } \\
1.1 \mathrm{~m}^{3} \text { full container } \\
{\left[\mathrm{m}^{3}\right]}\end{array}$ & $\begin{array}{l}\text { Number of containers } \\
\text { emptied to a } 22 \mathrm{~m}^{3} \\
\text { capacity vehicle [pieces] }\end{array}$ \\
\hline Paper & $20-30 \%$ & $0.88-0.77$ & $25-39$ \\
PET & $60-70 \%$ & $0.44-0.33$ & $50-67$ \\
bottle & & & $29-34$ \\
Metal & $30-40 \%$ & $0.77-0.66$ & $29-34$ \\
Glass & $30-40 \%$ & $0.77-0.66$ & \\
\hline
\end{tabular}

\subsection{Determination of the fullness of the containers}

With the integration of different type of distance sensors weight measuring devices and volume measuring devices it could be possible to get information about the exact saturation of the containers and it could provide further information about the container (Fig. 1). It is necessary to attach a communication device to the containers that can transmit the data provided by the sensors.

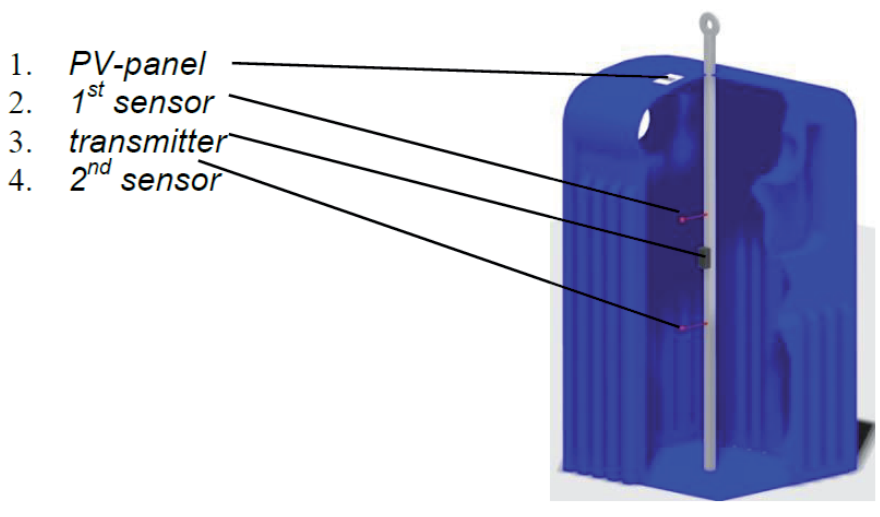

Fig. 1 Integrated measurement and communication device in the container

There are different methods to collect information about the amount of waste placed in the container:

- signal transmitted after the waste reaches a concrete level within the container,

- according to the number of pieces placed in the container,

- according to the waste's weight,

- with distance measuring equipment (ultrasonic distance measuring equipment)

Simplex communication is created between the container and the route planning center when the waste reaches a predefined level using the "signal transmitted after the waste reaches a concrete level within the container" method.

By the use of the other methods, it is possible to create duplex communication between the container and the route 
planning center and it is possible to get instant saturation information anytime.

\subsection{Information about the containers}

The system can provide further important information about the container:

- exact position of the container,

- incidental turnover of the container,

- $\quad$ specific errors (sensor failure, battery failure, etc.).

The data transmitted by the containers are stored and processed by the central computer. According to the statistics (saturation trend) processed about the containers, it is possible to determine the containers that aren't full at the moment but it can be saturated in the near future during the gathering. The container's saturation information could be useful for the users too. This information could be verified on the internet, so the user could select the container that capable to place the selective waste.

\subsection{Improved route optimization}

By the use of the route optimization devices - for example: GIS 3D modelling, ArcGis ${ }^{\circledR}$ and RouteViewPro ${ }^{\mathrm{TM}}$ - it is possible to create the optimal routes according to different options and it could be further developed by the communication with the database of the road authorities. The route planning center checks the road authorities' database and it plans the optimal route according to the fresh information about road maintenance or traffic order changes, so it is possible to create a more precise route definition.

\section{The system's review}

The following are the system's parts (Fig. 2):

1. selective waste container,

2. signal transmitter tower,

3. route planning center,

4. waste collecting vehicle.

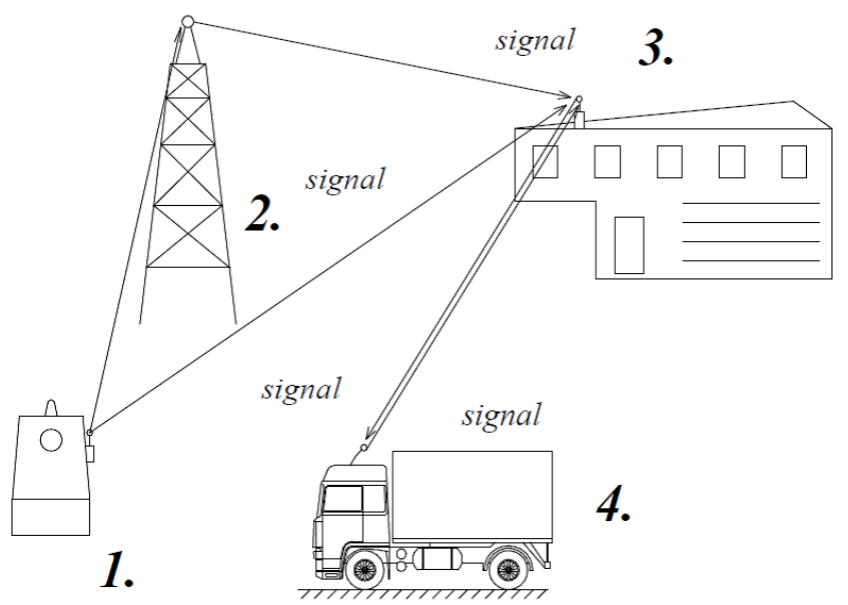

Fig. 2 Sign-in-time based info-communication system's abc and signal flow
Working of the system:

The data given by the measurement system placed in the containers are transmitted by the communication system. The data transmission to the route planning center can be done in two different ways. It can be done by using a direct long-range communication system (GSM), or it can be transmitted to a longrange communication center (signal transmitter tower/GSM) by a short-range communication system (Bluetooth) (Fig. 3).

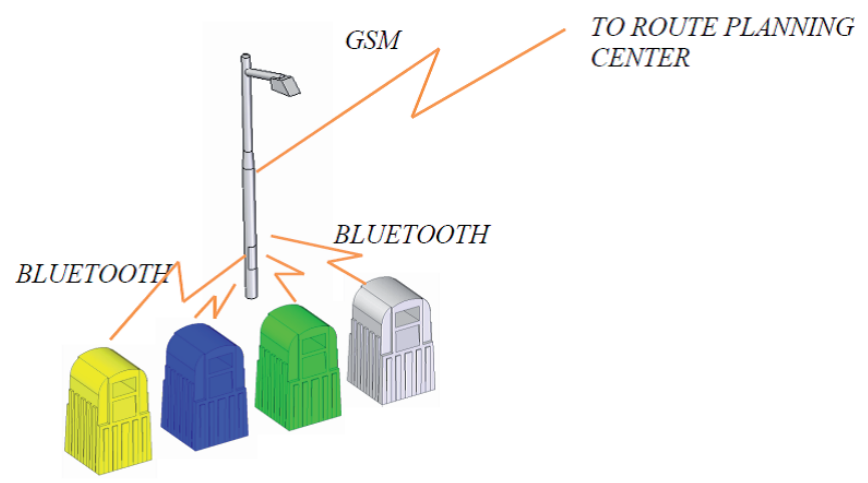

Fig. 3 Sign-in-time based short and long distance communication

According to the data received in the route planning center, the optimized routes are defined. By the use of the sign-in-time based system, it is possible to modify the routes and add new containers while the vehicle is on the way (Fig. 4).

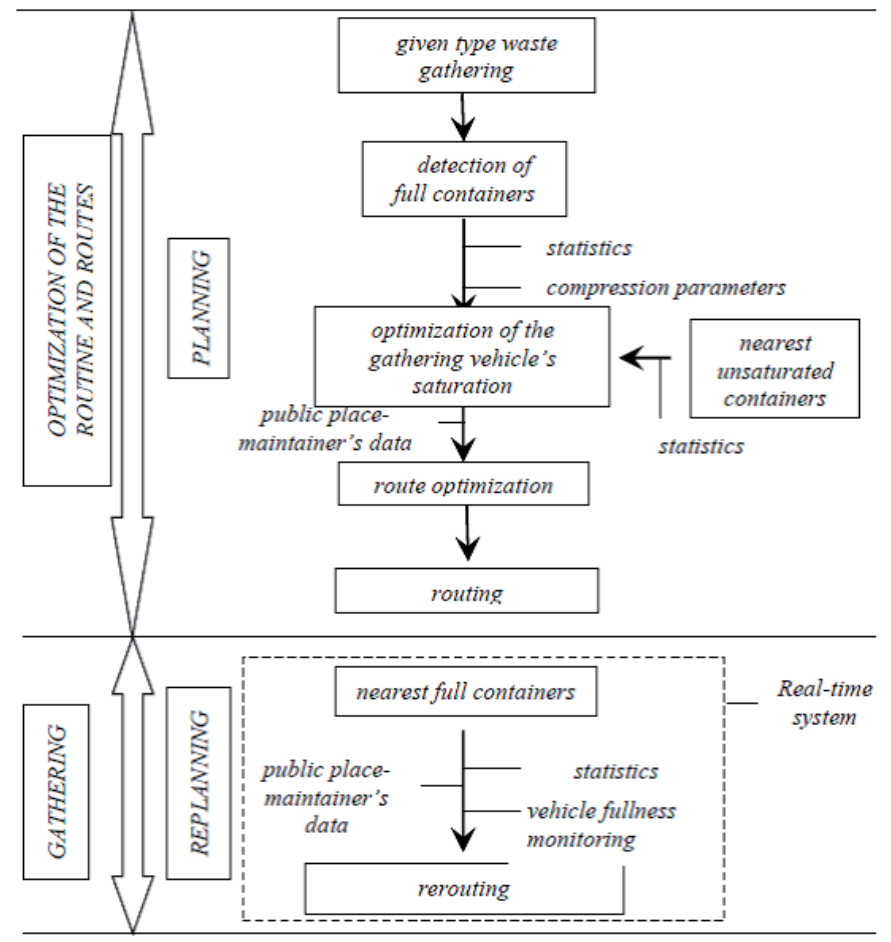

Fig. 4 Sign-in-time based info-communication system's waste gathering flowchart 
Expected advantages of the system:

The use of this system has more advantages than environmentalism, reduced emissions, sustainable development and cleaner, liveable cities (Fig. 5):

- environmental and road safety advantages

- operational advantages of the vehicles

- operational advantages of selective waste gathering containers

However, the following circumstances must also be taken into consideration:

- emptying process can be longer if beside frequently saturated containers more containers are settled for a good cause

- the saturation time of containers is different. Since they also have to be gathered, not only big capacity vehicles are needed, but special and smaller vehicle purchase is reasonable, which can generate additional costs.

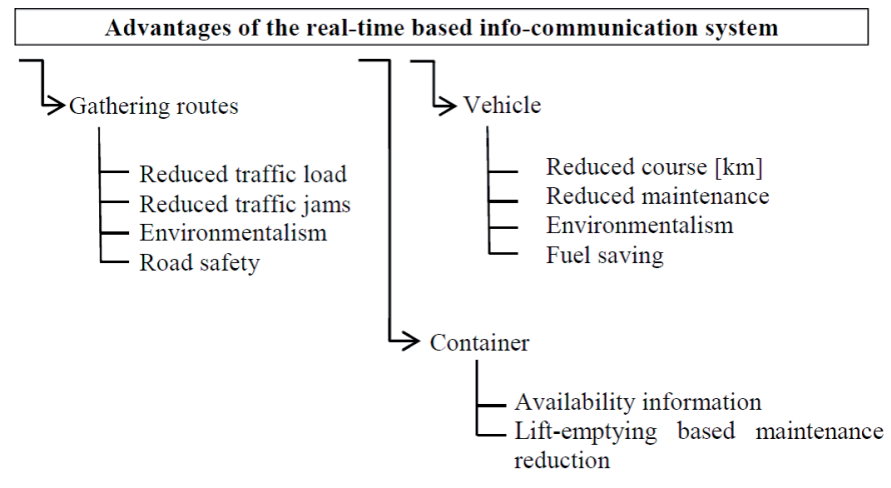

Fig. 5 The sign-in-time based info-communication system's advantages

\section{Conclusion}

By the use of the sign-in-time based info-communication system, the number of unjustified emptyings will drop off and the reasonable emptying will be done in time, so by the use of this system the development could be accessible for a cleaner and healthier city. By the use of this system, the environmental load could be significantly reduced and road safety could be increased. The statistical data received during the gathering process could be used for further development and it could prove the importance of the placement of new containers on the selective waste gathering stations. The publicity of the load data of the containers could allow the users to get information about which selective waste station should they use to place their waste and which container is capable for it.

\section{References}

Barlishen, K. D., Baetz, B. W. (1996) Development of a Decision Support System for Municipal Solid Waste Management Systems Planning. Waste Management \& Research, 14 (1), pp. 71-86.

DOI: $10.1177 / 0734242 X 9601400107$

Caruso, C., Colorni, A., Paruccini, M. (1993) The regional urban solid waste management system: A modelling approach. European Journal of Operational Research, 70 (1), pp. 16-30. DOI: 10.1016/0377-2217(93)90229-G

Chowdhury, S. A., Haque, B., Sarwar, G. (2014) Traffic Information Interface Development in Route Choice Decision. Transport and Telecommunication Journal, 15 (2), pp. 91-96. DOI: 10.2478/ttj-2014-0008

Fiorucci, P., Minciardi, R., Robba, M., Sacile, R. (2003) Solid waste management in urban areas: Development and application of a decision support system. Resources, Conservation and Recycling, 37 (4), pp. 301-328. DOI: 10.1016/S0921-3449(02)00076-9

Ghose, M. K., Dikshit, A. K., Sharma, S. K. (2006) A GIS based transportation model for solid waste disposal - a case study of Asansol Municipality. Waste Management, 26 (11), pp. 87-93. DOI: 10.1016/j.wasman.2005.09.022

Ko, J., Kim, D., Sin, H. G., Lee, S. (2014) The efficiency of vehicle monitoring locations for a voluntary travel demand management program. Transport, 29 (3), pp. 326-333. DOI: 10.3846/16484142.2014.953206

MacDonald, M. L. (1996) A multi-attribute spatial decision support system for solid waste planning, Computers. Environment and Urban Systems, 20 (1), pp. 1-17. DOI: 10.1016/S0198-9715(96)00006-3

Mihály, A., Németh, B., Gáspár, P. (2014) Integrated vehicle control of inwheel electric vehicle. Periodica Polytechnica Transportation Engineering, 42 (1), pp. 19-25. DOI: 10.3311/PPtr.7280

Jovičić, N. M., Bošković, G. B., Vujić, G. V., Jovičić, G. R., Despotović, M. Z., Milovanović, D. M., Gordić, D. R. (2010) Route optimization to increase energy efficiency and reduce fuel consumption of communal vehicles. Thermal Science, 14 (Suppl), pp. 67-78. DOI: 10.2298/TSCI100525067J

Péter, T., Fazekas, S. (2014) Determination of vehicle density of inputs and outputs and model validation for the analysis of network traffic processes. Periodica Polytechnica Transportation Engineering, 42 (1), pp. 53-61. DOI: 10.3311/PPtr.7282

Simonetto, E. O., Borenstein, D. (2006) A decision support system for the operational planning of solid waste collection. Waste Management, 27 (10), pp. 1286-1297. DOI: 10.1016/j.wasman.2006.06.012

Tadić, S., Zečević, S., Krstić, M. (2015) Ranking of logistics system scenarios using combined fuzzy ahp-vikor model. International Journal for Traffic and Transport Engineering, 5 (1), pp. 54-63.

DOI: $10.7708 /$ ijtte.2015.5(1).07

Tavares, G., Zsigraiova, Z., Semiao, V., Carvalho, M. (2008) A case study of fuel saving through optimization of MSW transportation routes. Management of Environmental Quality, 19 (4), pp. 444-454. DOI: $10.1108 / 14777830810878632$

Tettamanti, T., Milacski, Á. Z., Lőrincz, A., Varga, I. (2015) Iterative Calibration Method for Microscopic Road Traffic Simulators. Periodica Polytechnica Transportation Engineering, 43 (2), pp. 87-91. DOI: 10.3311/PPtr.7685

Titrik, Á., Lakatos, I., Orbán, T. (2011) Data determination of an internal combustion engine for model set-up. Hungarian Journal of Industry and Chemistry, 39 (1), pp. 35-40.

Titrik, Á., Széchenyi István University (2011) Optimalisation system for collecting selective waste. Patent P 1100734.

Tóth-Nagy, Cs., Jarrett, R., Conley, J., Clark N. (2006) Further Validation of Artificial Neural Network Based Emissions Simulation Models for Conventional and Hybrid Electric Vehicles. Journal of the Air and Waste Management Association, 56 (7), pp. 137-151.

DOI: $10.1080 / 10473289.2006 .10464513$ 